\title{
U.S. pharmaceutical policy in a global marketplace
}

\author{
Darius Lakdawalla, PhD, \\ RAND Corporation, 1776 Main St., Santa Monica, CA 90401 \\ Dana P. Goldman, PhD, \\ RAND Corporation, 1776 Main St., Santa Monica, CA 90401 \\ Pierre-Carl Michaud, PhD, \\ RAND Corporation, 1776 Main St., Santa Monica, CA 90401 \\ Neeraj Sood, PhD, \\ RAND Corporation, 1776 Main St., Santa Monica, CA 90401 \\ Robert Lempert, PhD, \\ RAND Corporation, 1776 Main St., Santa Monica, CA 90401 \\ Ze Cong, PhD, MPhil, \\ RAND Corporation, 1776 Main St., Santa Monica, CA 90401
}

Han de Vries, MPhil, and

RAND Europe, Westbrook Centre, Milton Road, Cambridge CB4 1YG, United Kingdom

Italo Gutierrez

University of Michigan, Ann Arbor, 238 Lorch Hall, 611 Tappan St., Ann Arbor, MI 48109

\begin{abstract}
Markets for innovative goods involve significant spillovers in a global economy. When US consumers pay higher prices for drugs, this stimulates innovation that benefits consumers all over the world. Conversely, when large European markets restrict prices and profits, foreign consumers bear some of the long-run cost in the form of less innovation. The result is a free-riding problem at a global level. These incentives are particularly strong for smaller markets, whose policies have relatively little impact on global innovation, but can have relatively large impacts on national pharmaceutical budgets. The result is a system in which the largest countries bear disproportionate burdens for stimulating innovation. Using a microsimulation approach, we estimate the impact of these incentive effects. The model's baseline estimates demonstrates that the US adoption of European-style price controls would harm consumers in the US and Europe; over a 50-year period, it would cost $\$ 8$ trillion in the US, and \$5 trillion in Europe. Similarly, repealing European price controls would add $\$ 10$ trillion to the wealth of US society, and \$6 trillion to wealth in Europe. Even under the most conservative assumptions, adopting price controls generates at best a small benefit, but risks a large cost. On the other hand, reducing pharmaceutical copayments would increase wealth in both societies, a result which is robust to a wide variety of parameter values.
\end{abstract}

\section{A. Introduction}

The United States is by far the largest market for pharmaceuticals. In 2005, the United States accounted for $42 \%$ of global sales, while Europe accounted for $29 \%{ }^{1}$ This difference is due

Corresponding Author: Darius Lakdawalla, PhD, RAND Corporation, 1776 Main St., Santa Monica, CA 90401,

Darius_lakdawalla@rand.org, Phone: (310) 393-0411.

${ }^{1}$ Out of the $\$ 600$ billion global market, the US accounted for $\$ 252$ billion, and Europe accounted for $\$ 171$ billion (IMS Health, 2006). 
in large part to more aggressive price negotiation by public insurance programs in Europe. While exact comparisons are difficult, the data suggest that European consumers pay $50 \%$ to $70 \%$ less for a given quantity of drugs. ${ }^{2}$

The higher profits in America contribute to the view of the United States as the engine for global pharmaceutical innovation. While some critics have questioned the link between profits and research and development (R\&D), the absence of R\&D into unprofitable thirdworld diseases and the increase in $\mathrm{R} \& \mathrm{D}$ for certain rare diseases after passage of the US Orphan Drug Act demonstrate otherwise. Evidence suggests that lower profits delay the launch of new drugs, limit the availability of new drugs, and ultimately reduce the pace of innovation (cf, Acemoglu and Linn, 2004; Finkelstein, 2004; Danzon, Wang, and Wang, 2005).

New treatments are of value to the entire globe, not just to the society that discovered them. Thus, spending by Americans encourages innovations that benefit both Europe and America, and the reverse is also true. There are certainly profits to be made in Europe, and these will affect the global pace of innovation as well. In this way, pharmaceutical pricing policies in Europe and the United States are inextricably linked.

Encouraging innovation poses important trade-offs for a single society, but it poses even more challenges in an integrated global economy. Firms will only undertake innovative activities if they expect to profit from them. However, the profits of innovators must be paid by consumers, either through out-of-pocket payments, premiums, or taxes to finance government provision. The patent system embodies this trade-off: new discoveries are rewarded with monopoly power, which leads to more expensive treatments, but it remains indispensable to the creation of new ideas. From a global perspective, therefore, it becomes important to understand who can, does, and should bear the cost for ideas with such broad benefits.

In this paper, we develop a model for analyzing the impact of global pharmaceutical policy on global welfare, with special attention to the spillovers between America and Europe. The model allows us to simulate the long-term consequences of pricing policies in the United States and Europe, and their attendant spillovers to consumers elsewhere. The heart of this exercise is a global microsimulation model of health and mortality, where morbidity and mortality are affected by baseline health, health behavior, as well as rates of innovation. In turn, innovation is affected by public policy variables, both in the US and abroad.

\section{B. Policy Background}

We will focus on the broad differences between the United States and Europe, but it bears mentioning that European countries differ in the type and extent of regulation imposed on the pharmaceutical marketplace. It is nonetheless generally true that-when it comes to pricing drugs--all European markets are more heavily regulated than the US market. A companion paper, "The Effect of Pharmaceutical Regulations on Sales," contains much more detail on the precise nature of regulations in Europe. As discussed in much more detail there, these regulations consist of direct and indirect price controls, constraints on prescribing budgets, economic evaluations of drugs, and policies for increasing generic use.

That paper's empirical analysis quantified the extent to which regulations of various types decrease pharmaceutical revenues, relative to the US market. We use those estimates to

\footnotetext{
${ }^{2}$ These numbers are based on 2005 aggregate prices in the US and individual European countries. Aggregate prices are constructed using data on total expenditures, and total quantity (in terms of standardized units), as reported by IMS Health.
} 
simulate the effect of rolling back regulations in Europe, and conversely, of instituting certain European-style regulations in the US market.

It would be infeasible to tease out all the revenue and utilization effects of the many and varied regulations in the European marketplace. For conceptual clarity, therefore, we focus our attention on two kinds of regulations - price controls, and co-payment reductions that have different effects on revenues and utilization. The earlier paper showed that price controls (or, more specifically, price-negotiation) are extremely prevalent in Europe, and that they lower pharmaceutical revenue by about $22 \%$. In part to distinguish it from a copayment subsidy, we think of these price controls as occurring only on the manufacturer side, in the sense that they depress revenues to innovators, without affecting what the patient pays out-of-pocket. In contrast, co-payment subsidies lower prices patients pay; all else equal, this increases consumer utilization and innovator revenues. Therefore, we also consider co-payment reductions of an equal amount.

In this paper, we consider the global impact — on health and welfare — of "repealing" direct price controls in Europe, and of imposing direct price controls in the US. More specifically, we simulate the effects of raising revenue by $22 \%$ in Europe, and of lowering it by $22 \%$ in the US. The importance of this policy simulation owes itself to the widespread nature of these policies in Europe, and to growing calls in the US for Medicare to engage in some kind of price-negotiation with pharmaceutical firms, the effect of which would be qualitatively similar to direct price controls.

As a complement to this analysis, we simulate the effects of lowering the out-of-pocket costs of US consumers by $22 \%$, and of raising the out-of-pocket costs of European consumers by the same amount. The price controls scenario analyzes the impact of changing prices paid to manufacturers, ceteris paribus, while the copayment scenario analyzes changes in consumer prices, holding manufacturer prices fixed. The copayment scenario is of interest partly because Medicare Part D recently lowered out-of-pocket costs for many Medicare beneficiaries. More generally, co-payment reductions represent a stark contrast to price control policies: they can boost revenues, utilization, and public sector spending on pharmaceuticals. A comparison of these two extremes may prove useful.

\section{Overview of Model}

We developed a demographic and economic model to predict costs and health status for the US and European population over the age of 55. A crucial component was a model of how new innovations are discovered, and how they impact the health transitions of this population. The Global Pharmaceutical Policy Model (GPPM) is a microsimulation model that tracks a US-representative sample of 55+ year-olds, and a similar Europeanrepresentative sample, over time to project their health conditions, functional status, health expenditures, and mortality experience. Much more detail is provided in an online technical appendix. We summarize its crucial features below.

\section{C.1 Model Layout}

Conceptually, the GPPM begins with longitudinal data on respondents in the US and Europe. The longitudinal aspect of the data allows us to construct probabilities of transition from one health state to another. These transitions are then used to simulate the "aging" of the respondents, in the context of the model.

The model recognizes that health transitions depend on available health care technology. It thus incorporates the probability of new pharmaceutical breakthroughs as a key model parameter. The baseline simulations use historical rates of pharmaceutical breakthroughs, 
but policy simulations use estimated changes in this rate, and thus forecast the long-run health effects of those changes.

The likely health effects of pharmaceutical breakthroughs are calculated. We use clinical trial data on the health effects of new drugs, along with empirical estimates of how much new drugs increase access to therapy.

Figure 1 outlines the basic structure of the model. We begin with information on the health of the population, at time $t$. This is used to predict health in $t+1$, based on hazard functions for diseases, disability, and mortality. It also determines the size of the pharmaceutical market at time $t$, and the revenues earned by innovators at time $t$. Since innovation occurs with a lag, the level of revenues delivers estimated impacts on the number of new drugs in period $t+10 .^{3}$ The health effects of these new drugs are then used to adjust the health hazard functions at that time. Finally, since the "aged" sample is no younger than 56, we "refresh" it by adding HRS 55 year-olds; this imposes the thought experiment that baseline health remains stable in this population. At this point, the model proceeds with the time $t+1$ population, and the cycle begins anew.

The model includes policy levers that affect the size of markets, and the utilization of drugs: we allow for regulation of the price paid to manufacturers, and regulation of the price paid by consumers. Regulating the manufacturer price affects the revenues of pharmaceutical firms without affecting consumer utilization, at least in the short-run. In the long-run, the model includes a feedback between pharmaceutical revenue and the number of new drugs coming to market. Regulating consumer price affects both consumer utilization, and the revenues of innovators. The policy levers are discussed in greater detail in the context of our policy simulations below.

\section{C.2 Modeling Health Transitions for the US and Europe}

C.2.1 Data source for the United States-We use the Health and Retirement Study (HRS), a nationally representative longitudinal study of the age 50+ population as our main source of data for the US. ${ }^{4}$ We use the observed medical history of respondents to the rate at which diseases are contracted, as a function of current health conditions, age and other socio-demographic characteristics (sex, race, risk factors such as obesity and smoking). The data are recorded roughly every 2 years, from 1992 to 2002, along with information on baseline disease prevalence in 1992. Due to the sparseness of the HRS cohort at age 50, we use the sample over the age of 55 for all our modeling exercises. In addition, our baseline scenarios use the 55 year-olds to "refresh" the model each period. This holds fixed the health and demographic characteristics of our study population, and focuses attention on the changes in policy and innovation.

The first numerical column of Table 1 shows the baseline characteristics of the HRS respondents aged 55+, along with the list of risk factors and health conditions used by the simulation model. We model the incidence and prevalence of mortality, functional limitation (disability), and the following seven diseases: heart disease, hypertension, diabetes, cancer, lung disease, stroke, and mental illness. Each of these diseases is an absorbing state. All these conditions are self-reported in the HRS; mortality is recorded from exit interviews and closely tracks the associated population survival rates.

\footnotetext{
${ }^{3}$ For the first 10 years of the simulation, the rate of new drug introduction is assumed constant, fixed at its baseline level.

${ }^{4}$ To obtain a sample that is representative of the entire 50+ population, we use all HRS cohorts: the original cohort, the AHEAD (Asset and Health Dynamics of the Oldest-Old) cohort, the "War Babies" cohort, and the CODA cohort.
} 
C.2.2 Data Source for Europe-The Survey of Health, Ageing, and Retirement in Europe (SHARE) is a multidisciplinary and cross-national database of micro data on health, socioeconomic status, and social/family networks of individuals aged 50 and over, in eleven European countries. It was modeled after the US HRS; this comparability makes it particularly attractive for our application. Based on probability samples in all participating countries, SHARE represents the non-institutionalized population aged 50 and older. The first wave of SHARE is in 2004.

Baseline characteristics of the SHARE sample are shown in the second numerical column of Table 1. Viewed broadly, the US and European populations look fairly similar in terms of demographics. However, disease prevalence differs, with Americans being sicker than Europeans, a finding that has been reported elsewhere in the literature (Banks et al., 2006). According to earlier research, most of these disease differences reflect real differences in health, but one exception is in mental problems, where at least some differences arise due to different definitions in the surveys. ${ }^{5}$ There is no obvious reason for the difference in reported disability, but it should be noted that self-reported disability contains an important element of subjectivity (for a discussion of this issue, see Banks et al., 2005).

\section{C.3 Hazard Estimation}

The "engine" of the model is a set of hazard functions that simulate aging, mortality, along with the onset of disease and disability for the sample members. The occurrence of all seven diseases, along with functional limitation, and mortality, is simulated using hazard functions estimated from the data.

Specifically, individual $i$ at age $t$ has the following hazard of developing condition $c$ :

$$
h_{i c t}^{*}=x_{i} \beta_{c}+h_{i, t-1, c} \gamma_{c}+\eta_{i c}+a_{c t}+\varepsilon_{i c t}
$$

The variable $h_{i c t}^{*}$ is the "latent risk" of condition $c$. An individual has condition $c$ if her latent risk exceeds zero. The hazard of developing the condition depends on: $x_{i}$, individual $i$ ' $s$ baseline risk characteristics; $h_{i, t-1,-c}$, individual $i$ 's health conditions (other than $c$ ) in the previous period; $\eta_{i c}, i$ 's individual-specific propensity to develop condition $c$; $a_{c t}$, an agespecific effect on the risk of acquiring the condition; and $\epsilon_{i c t}$ an idiosyncratic random shock at age $t$, that has an extreme value distribution. This model allows for individuals to vary both in their baseline risk characteristics, and their unobserved propensity to develop specific diseases. That is, we allow for the fact that some individuals are "sicker" or "healthier" than others, in ways that are unobservable to the analyst. We estimate from the data the correlation in the distribution of these unobserved heterogeneity terms.

For each condition $c$, we estimate equation 1 using the entire HRS sample of individuals aged 50 and above. The estimated hazard functions, which appear in our technical appendix, form the basis of the "aging" process in the model. The variables $\eta$ and $\epsilon$ are random components. At the start of every simulation, and based on the empirical distribution of $\eta$ apparent in the HRS data, we draw a set of $\boldsymbol{\eta}$ 's for each individual. These determine the underlying frailty and health of each person. Next, in each period, we draw a separate $\epsilon$ for each individual and condition. Using the values of $\eta, \epsilon$, the estimated hazard functions, and

\footnotetext{
${ }^{5}$ The HRS asks whether or not a doctor has ever told the respondent that he/she has emotional, nervous, or psychiatric problems. In contrast, SHARE asks a much more expansive question, whether there has been a time or times in your life when you suffered from symptoms of depression which lasted at least two weeks? We also consider the follow-up question in SHARE that asks whether this was diagnosed by a doctor.
} 
the individual's covariates, we then derive a predicted hazard value $h_{i c t}^{*}$. If this value exceeds 0 for a condition, the individual acquires it.

\section{C.4 Incorporating the Effects of Pharmaceutical Breakthroughs}

There are several steps to incorporate the effects of new drug introductions: calculating the number of new drugs, how this number responds to changes in the policy environment, assessing their impact on health transitions, and valuing these impacts. Given the sheer number of total molecules that are developed, and the wide variance in their success, it would be impractical to estimate the health effects of all new molecules. Instead, we make the conservative assumption that only the best new drugs - "top-sellers" - improve health. Therefore, we estimate the probability that a given drug is a top-seller, and then the average health improvement associated with a top-seller drug. Implicitly, this assumes that non-topseller drugs have no impact. A companion paper, "The Health Effects of New Drugs", gives a complete description of our approach. We summarize the main steps below.

C.4.1 The Health Effects of New Drugs-We begin with a baseline set of past "topseller" drugs. To construct this set, we start with the set of all drugs developed between 1996 and 2003. For each of our seven conditions, we identify the five top-selling drugs used by people with that condition, using sales in the drug's second year. Drugs are excluded from the list for a relevant condition if they are not used to treat that particular condition; for example, Lipitor (a cholesterol-lowering drug) appeared on the list for cancer, but was excluded from that list, according to this criterion.

The total health effect of a new top-seller drug is composed of its "clinical effect" and its "access effect." The clinical effect is the increase in efficacy over earlier treatment. The access effect is the extent to which the new drug increases utilization, perhaps by reducing side effects. The clinical effect improves outcomes for those already on an existing drug, but who switch to the new therapy. The access effect improves outcomes for those afflicted by the disease but as yet untreated.

The clinical effects are calculated by surveying the medical literature for clinical trials testing 35 top-seller drugs on our list ( 5 drugs for each of 7 conditions). When the trials do not provide an estimate for the health condition we are interested in, we assume the drug has no effect. Hence, these estimates can be seen as conservative. We do the same when the estimate is not statistically significant. When more than one estimate is available, we use the mean of the effects found.

To calculate the access effect, we empirically estimated the decrease in the fraction of untreated individuals following the introduction of a new drug. In particular, we estimated the effect of top-seller launches on the total number of monthly prescriptions written in that drug's therapeutic class. We estimate that top-seller launches increase class-level prescriptions by $26 \%$ after one year.

C.4.2 The Rate of New Drug Introductions-The next step is to calculate the rate at which new top-seller drugs are introduced. This is based on empirical FDA approvals, between 1998 and 2002. Over this period of time, we calculated the total number of FDA approvals for each of our 7 diseases, as well as the total number of "top-seller" drugs approved. These numbers are used to estimate the average annual number of new drugs, and of new top-sellers.

Every year, the number of new top-sellers in a disease category is constructed as the probability of a top-seller for that specific disease, multiplied by the number of new drugs in the disease class. The number of new drugs in a disease class varies with the number of 
patients afflicted, who make up the market for that set of drugs. A critical parameter in the model is "innovation-responsiveness," or the relationship between changes in market size and changes in the number of new drugs. In particular, we need a parameter that translates a given increase in market size (in terms of patients with a disease), into an effect on the number of new drugs.

Our parameter is based on an estimate from the empirical literature. Previous research has found that, on the margin, a one percent increase in pharmaceutical revenues leads to a four percent increase in the annual number of new drugs (Acemoglu and Linn, 2004). We use this value of four in our baseline scenarios, but consider a range of estimates from zero to five. In addition to Acemoglu and Linn, there is a great deal of evidence that the elasticity is strictly greater than zero, making this a useful lower bound for robustness analysis. In particular, if innovators did not respond to changes in revenues, it would be impossible to explain why vaccine introductions rose with subsidies for vaccine purchase (Finkelstein, 2004), or why pharmaceutical companies seem to delay launches of new drugs in countries with greater degrees of price regulation (Danzon, Wang, and Wang, 2005).

Assuming that revenues are proportional to the number of sick consumers, we can readily translate the elasticity into a parameter that relates market size to new drugs. In our baseline year, the empirical literature suggests that a one percent increase in the number of sick consumers leads to a four percent increase in the number of new drugs. Since we know the baseline levels of sick consumers in each disease group, and the number of new drugs in each disease group, this implies a relationship between patients and new molecules.

Table 2 illustrates our method. We begin with the estimated annual number of new drug introductions in each disease group, and the number of patients (in 2005) with each disease. These are shown in the first two rows of the table, for each disease. If the elasticity of new drug introductions is 4.0 , then a one percent increase in market size generates a four percent increase in the number of new drugs. These calculations are displayed in the third and fourth rows of the table. We then compute the number of new patients required to generate a single drug - this is simply the ratio of the increase in market size (of 1\%), to the increase in the number of new drugs (of $4 \%$ ). This is the last row of the table. Varying the elasticity from $4 \%$ to other values is straightforward, and causes our estimate of market size per drug to vary correspondingly.

This method provides us with the number of new drugs for each disease. The probability of a top-seller in each disease group is then applied to these results to generate the number of new top-sellers each year. We allow for a 10 year lag between the time between the start of research, and the date of launch. This is approximately equal to the average time required for a drug launch in the U.S. Hence, new drugs in a given year depend on changes in market size 10 years ago.

C.4.3 New Drugs and Health Transitions-The last step is to combine our findings for the number of new top-seller drugs, and the health effects of those drugs, so as to forecast the impact of new drug introductions on health transitions in our model. The basic approach is to estimate the impact of new drug introductions on the probability of acquiring an illness, and use this to adjust the hazard of acquiring that illness.

Specifically, we adjust the estimates $\gamma_{c}$, to account for the impact of new drugs on the incidence of disease, for a specific group of patients. For example, we estimate the impact of new drugs on the probability that heart disease patients will develop stroke, the probability that hypertension patients will develop heart disease, and so on. 
Consider the risk that people with disease $A$ will develop disease $B$. We need to estimate the impact of new drugs on the incidence of $B$ for the population with $A$. In the simplest possible terms, we calculate the ratio:

$$
R R=\frac{P_{n e w}^{A B}}{P_{\text {current }}^{A B}}
$$

$P_{\text {current }}^{A B}$ is the baseline probability that people with disease $A$ will develop $B . P_{\text {new }}^{A B}$ is the probability after the top-seller drug introduction. Details of the calculation appear in the companion paper "The Health Effects of New Drugs." However, in simple terms, we estimate $P_{\text {current }}^{A B}$ as the empirical probability that HRS respondents with $A$ develop $B$. $P_{\text {new }}^{A B}$ is estimated by combining the clinical effect of the new top-seller introduction, with the access effect. The new drug will improve the health of those who are already treated (clinical effect), and it will improve the health of those who are currently untreated, by expanding access to the drug (access effect).

C.4.4 Valuing Health Improvements-Once we have estimated changes in health and longevity, it remains to value these in a way that can be compared with spending on drugs and medical care. We adopt the relatively conservative assumption that innovation generates value only through improvements in longevity.

Extensions (or reductions) in life expectancy are assigned a value for a statistical life-year. There is a large and controversial literature on the economic value of a life-year. In a wellknown and widely cited literature review that continues to be cited and used today, Viscusi (1993) concluded that the best available range of values for a statistical life-year spans $\$ 200,000$ to $\$ 470,000$ (values are inflated to 2004 dollars). Lower values are sometimes used by regulatory agencies, particularly in Europe. For example, the United Kingdom's National Institute for Health and Clinical Excellence (NICE) often values additional lifeyears anywhere from $\$ 40,000$ to $\$ 70,000$.

In our baseline analyses, we adopt a middle-of-the-road estimate, of $\$ 200,000$. However, in our sensitivity analysis, we consider values that span $\$ 50,000$ to $\$ 300,000$.

C.4.5 Evaluating Medical Care and Drug Costs-Because the HRS does not have accurate information on total medical expenditures and total drug expenditures, we use the Medical Expenditure Panel Study (MEPS) to estimate average cost in the U.S.. We regress expenditures on the same demographics we have in the model as well as age and health condition indicators. Few differences in the definition of variables are observed. We use the sample of age 50+ individuals in MEPS. The regressions are performed separately for male and female as well as for each type of expenditure (drug and medical). Since the MEPS is known to underestimate costs at older ages, we use the Medicare Current Beneficiary Survey (MCBS), a survey using Medicare claims data, to adjust average cost in the MEPS. Since cost is usually lower in Europe than in the U.S., we adjust average cost using the OECD figures on expenditure per capita. This adjustment lowers medical care costs by an average of $57.9 \%$ in Europe and drug costs by $36.2 \%$. The online technical appendix provides more detail on these adjustments.

\section{Global Effects of Policy}

The GPPM is used to estimate the global impacts of regulation in the European and US markets. We explore three kinds of policy scenarios: (1) Price controls; (2) Copay reductions; and (3) Status quo. 
As discussed earlier, we simulate price controls as reducing prices and revenue by $22 \%$. Therefore, we suppose that adopting price-negotiation in the US would lower pharmaceutical revenues (and prices paid to manufacturers) by $22 \% .{ }^{6}$ Conversely, we also consider the repeal of European price-negotiation, and suppose that this would raise revenues (and prices) by 22\%. Decreases in manufacturer prices: lower current drug spending, but leave current utilization unchanged; lower revenues and the future rate of innovation; and have uncertain effects on medical spending.

The price-negotiation scenario examines variation along the margin of manufacturer prices. We introduce variation in consumer prices by modeling the impact of changes in consumer copayments. Specifically, we consider the impact of "passing through" the changes induced by price-negotiation policy. We investigate the impact of lowering consumer copayments by $22 \%$ in the US, and raising them by $22 \%$ in the EU. Decreases in the copayment: increase utilization and drug spending; raise revenues and the future rate of innovation; and have uncertain effects on medical spending.

To evaluate the welfare implications of each policy scenario, we focus on the key dimensions of health and medical spending. The model simulates gains (or losses) in life expectancy due to these policy choices; as mentioned earlier, the baseline simulations value these gains using $\$ 200,000$ as the value of a statistical life-year. In addition, price control policies are often motivated by a desire to contain costs. Therefore, we also calculate the impact on both drug spending and medical spending. The net present value of a particular policy is given by: the present value of life expectancy, less the present value of medical spending and drug spending.

\section{D.1 Global Effects of New Regulations in the United States}

D.1.1 US Price Controls-We begin by analyzing the effect of new regulations in the United States. Introducing price controls - or, more generally, lowering manufacturer prices by $22 \%$ while leaving consumer copayments unchanged - would affect the pace of innovation, as well as health care spending. The net value of a price controls strategy derives from its impact on longevity, and on spending. Figure 2 illustrates the impact of introducing US price controls on the longevity of 55-59 year-old cohorts. The figure shows that the introduction of price controls would reduce life expectancy by two-tenths of a year for 5559 year-old Americans alive in 2010, and by one-tenth for 55-59 year-old Europeans alive in the same year. The longevity effects are larger for the older cohorts, because the effects of price controls on innovation accumulate over time. In our model, for instance, changes in revenues do not affect rates of innovation for at least 10 years. Therefore, the 2010 cohort is not exposed to its innovation effects for that initial period of time. In contrast, the later cohorts are exposed to heavier doses. By 2060, 55-59 year-old Americans lose almost 0.6 years of life expectancy due to US price control implementation, while 55-59 year-old Europeans lose around half a year.

On the benefit side, US price controls reduce spending on drugs and medical care. Figure 3 quantifies this effect. Price controls adopted in 2005 would reduce lifetime per capita spending on health care by $\$ 9100$ in the US, and $\$ 300$ in Europe, for 55-59 year-olds alive in 2010. The reductions in Europe come about due to the slight reduction in life expectancy. The US effects combine life expectancy reductions with direct reductions in cost. For 55-59 year-olds alive in 2060, Americans can expect \$13,300 less in lifetime spending, while Europeans can expect $\$ 1600$ less.

\footnotetext{
${ }^{6}$ Implicitly, we assume that price-negotiation alone does not affect consumer prices, and thus utilization. As such, the percentage change in revenues is equal to the percentage change in price.
} 
A rough comparison of these numbers with the changes in life expectancy suggests that the reduction in life expectancy will outweigh the health care savings, even at very low values of life. If one were to transform the change in raw life expectancy into a change in discounted life-years, this would reduce the life expectancy costs by about one-third. Even after this adjustment, and even using a $\$ 50,000$ value of a statistical life-year, it is clear that the reductions in longevity will be costly, on balance.

Figure 4 demonstrates this reasoning. The figure shows that US price controls are costly, imposing net present per capita costs of $\$ 3000$ and $\$ 6000$ on the 2010 cohorts of Americans and Europeans, respectively. The cohorts exposed for longer periods to the effects on innovation suffer even larger costs. Each 55-59 year-old alive in 2060 can expect to face a cost of $\$ 44,000$ and $\$ 34,000$ in the US and Europe, respectively.

Of course, the oldest members of the earliest cohorts gain from price controls. To take an extreme example, an individual with one year to live would gladly accept price controls, because innovation effects will post-date his death. Therefore, it is important to add up the total burden on the entire elderly population, as in Figure 5. For the earliest cohorts, the total net cost is positive, but small, at least in comparison to the costs imposed on later cohorts. The 2060 cohort of 55+ year-olds, on the other hand, experiences net costs of $\$ 8.1$ trillion in the US, and \$5.2 trillion in Europe.

D.1.2 US Copay Reductions-Reductions in manufacturer prices reduce the pace of innovation and lower spending. In and of themselves, reductions in consumer prices do the opposite: they stimulate innovation by raising utilization of drugs, and thus raising revenue; and they raise spending for the same reason. They can be expected to have the opposite effect on longevity and spending. Copay reductions couple a stimulus to innovation with a direct increase in the utilization of drugs, which might be expected to magnify the benefits of more rapid innovation.

Figure 6 illustrates the longevity impact of a similar-sized reduction in US consumer copays. The earliest cohorts in the US and Europe can expect to gain about one-tenth of a life-year from additional innovation, while the latest cohorts experience 0.3 to 0.5 year increases in life expectancy. These are slightly smaller than the costs imposed by adopting price controls. It is important to note that the effects of combining the two policies would not be additive in nature, even approximately. Therefore, one cannot infer from these figures the effects of implementing both policies at the same time.

Figure 7 illustrates the impact of copay reductions on health care spending. As before, the growth in health care spending is substantially smaller in magnitude than the growth in longevity, even for relatively small values of life-years.

Figure 8 and Figure 9 put together the longevity and health care spending numbers to produce the net value of the US copay reduction policy. Figure 8 reports this in terms of per capita value to cohorts of 55-59 year-olds, while Figure 9 shows total value to cohorts of $55+$ year-olds. The earliest cohorts of 55-59 year-olds experience slight improvements in welfare, equal to approximately $\$ 1700$ and $\$ 5500$ per person, in the US and Europe. The increase in innovation slightly outweighs the short-run increase in spending on drugs. The later cohorts experience even larger benefits, equal to $\$ 31,500$ per American, and $\$ 23,400$ per European. The overall change in wealth for $55+$ year-olds is equal to $\$ 6.8$ trillion and $\$ 3.0$ trillion to Americans and Europeans in 2060. The total effects on the 2010 cohorts are at or less than $\$ 200$ billion, which is negligible compared to the later benefits. 


\section{D.2 Global Effects of Repealing Regulations in Europe}

In Europe, we study the effects of repealing price controls, and of increasing copayment rates. These are essentially the mirror images of the US policies, and they have predictably symmetric results.

Figure 10 and Figure 11 present per capita and total net present values for repealing EU price controls. On a per capita basis, the 2010 cohort reaps a per capita benefit equal to $\$ 7800$ in the US and $\$ 9200$ in the EU. The 2060 cohort, on the other hand, receives per capita benefits equal to $\$ 49,700$ and $\$ 38,700$ in the US and EU. The total value to the all $55+$ year-olds in 2050 is $\$ 9.6$ trillion in the US, and $\$ 6.2$ trillion in the EU. The early 55+ cohorts derive little or no benefit, although the sizes of these effects are extremely small compared to the later cohorts.

Figure 12 and Figure 13 show the analogous results for increasing EU copayment rates. On a per capita basis, this policy costs $\$ 18,500$ and $\$ 36,000$ in the US and EU, respectively, for the 2060 cohort of 55-59 year-olds. On a total value basis for the entire 55+ population, the policy costs $\$ 2.5$ trillion and $\$ 4.9$ trillion in the US and EU, respectively.

\section{D.3 Sensitivity Analysis}

The robustness of the model's policy implications clearly depend on the robustness of its parameters. Since there is uncertainty about the precise values of several key parameters, we analyze the sensitivity of our conclusions to variation in those values. We find that our qualitative conclusions are unaffected by variation in all parameters, except for the responsiveness of innovation to revenues.

Figure 14 displays the sensitivity of the model to variation in the value of a statistical lifeyear. The Figure shows how the value of a statistical life-year affects the global net present value (to the 2060 cohort of 55-59 year-olds) of all four policy interventions, relative to the status quo. The only benefit of innovation we consider is mortality reduction. Changes in the value of a statistical life-year have a linear impact on the value of these benefits. Moreover, the value of life has no direct impact on costs. As a result, the overall impact of this parameter is linear. The figure illustrates that the qualitative predictions of the model regarding which policies are beneficial and which are costly - do not depend on the value of a life-year. We consider values from $\$ 50,000$ to $\$ 300,000$, a range which encompasses all widely used values for this parameter. To be sure, higher values of life translate into larger costs for price controls, and lower benefits for copayment reduction, because the value of stimulating innovation is positively related to the value of life.

Another important parameter in the model is the likelihood that a blockbuster will appear. We estimated this parameter empirically, for each of our disease categories, using actual drug introductions from 1998 to 2002. The mean probability of a top-seller in each disease was used in our baseline estimates. To conduct sensitivity analyses, we vary the parameters uniformly over their respective confidence intervals. For example, we reduce all probabilities so as to place them $25 \%$ of the way between their mean and the bottom of their confidence interval, $50 \%$ of the way, $75 \%$ of the way, and at the bottom of their confidence intervals. We repeat the procedure, in reverse, to inflate the values of this parameter. Figure 15 displays the results. Not surprisingly, when the probability of a blockbuster gets smaller, so do the values of copayment reductions and the cost of price controls. However, for the most part, this affect only the magnitudes of our cost and benefit estimates, rather than their direction. The one exception to this is for US copay reduction. When the probability of a blockbuster gets taken to the bottom of its confidence interval - so that the value of new drugs is minimized - copayment reduction costs $\$ 0.1$ trillion. This is virtually the only parameter value for which copayment reduction is not a strictly welfare-improving policy. 
Figure 16 varies the access effect across the width of its confidence interval. On average, the launch of a new top-selling drug expands access by $26 \%$. The confidence interval around this mean ranges from $2 \%$ to $50 \%$. Therefore, we consider values from zero to fifty percent. When the access effect is zero, all the benefits of innovation are derived from the model's clinical effect, which are quite modest. At this point, US price controls cost the 2060 cohort of 55-59 year-olds about $\$ 200$ billion, compared with about $\$ 1$ trillion in the baseline scenario. Note the non-monotonicity in the value of copayment reductions, with respect to the access effect. There are two competing forces: a higher access effect makes innovation and policies that stimulate it - more valuable; on the other hand, when innovation stimulates access, there is less return to policies that stimulate access by lowering consumer prices. There is also a small non-monotonicity in the value of price controls. At higher access effects, total drug consumption is higher, so that the pure financial savings from price controls are also higher. This financial effect becomes dominant at very high access effects, where the incremental gains from treating more people become smaller.

The last component to the value of innovation is the clinical benefit of new top-selling drugs. This was computed using a review of the medical literature, and fairly rigorous standards for demonstrating a clinical benefit. The clinical effects used in our baseline calibration were quite modest - only cancer and lung disease showed much of any clinical benefit to innovation, by our standards of evidence. Therefore, we consider the impact of raising the clinical benefits. The sensitivity analysis compares our baseline results to two alternative scenarios. The "optimistic" scenario assigns to all diseases the clinical effect of innovation on mortality estimated for lung disease, which exhibits the biggest effect. The "medium" scenario is located halfway between the baseline and optimistic. As expected, the clinical benefits have substantial impacts on the model's implications. The optimistic scenario suggests that price controls are 8 times as costly as the baseline estimates suggest.

The last parameter we analyze, and the one with the most important qualitative impact, is the responsiveness of innovation to revenues. Estimates in the economics literature suggest that a one percent increase in pharmaceutical revenues leads to a four percent increase in the number of new molecules (Acemoglu and Linn, 2004). However, the paucity of estimates in the literature warrant caution in calibrating this parameter. As a result, we consider values ranging from zero to 5.0. As argued earlier, several papers in the literature suggest that innovators respond, at least a little, to changes in revenues. Therefore, zero seems a strict lower bound on this parameter. Figure 18 plots the impact of changes in this parameter on the net present value of policy to cohorts of 55-59 year-olds. Depending on the value of this parameter, US price controls can generate $\$ 100$ billion of benefit to the 2060 cohort, or impose up to $\$ 2.5$ trillion in cost. Below a value of 2.0, price controls become beneficial. The key drawback of price controls is not their obvious costs or benefits, but instead their risk. On the other hand, copayment reductions remain beneficial throughout, as long as innovation responds to revenues at all - a relationship that has been repeatedly verified in the empirical literature.

\section{E. Discussion}

When innovation-responsiveness is relatively low, US price controls may create small but positive benefits for consumers. When it is high, however, the same policies are extremely costly for consumers. As such, price controls represent a risky policy strategy that may have modest pay-offs, or large costs, depending on the responsiveness of innovation. On the other hand, copayment reductions are a robust policy strategy that provides benefits regardless of parameter values. Given the inherent uncertainty about the innovation parameter, copayment reductions may represent the more broadly beneficial policy choice. 


\section{F. Concluding Remarks}

We have explored the impact of alternative pricing regimes, in the US and Europe, on global welfare. Our approach has emphasized the linkages created by the global nature of innovation. For example, implementing price controls in the US would have adverse effects on European consumers, by depressing rates of innovation. Conversely, repealing European price controls would benefit US consumers.

These global linkages create significant policy problems in an international marketplace, because a given country does not fully realize the benefits (or costs) of its own policies. European price controls, for example, have smaller effects on innovation, due to the presence of the larger US market, which acts as a counterweight to policies that reduce European revenues. Moreover, some of the costs that do accrue end up being borne by US consumers, further dampening Europe's incentives for higher prices.

Our model illustrates that, from a long-run global perspective, reducing copayments tends to be a robust and welfare-improving policy, while imposing price controls tends to reduce welfare, possibly by a great deal. Policymakers facing uncertainty about the structure of pharmaceutical markets may find copayment reduction to be a safer strategy than price controls, and one that is extremely likely to improve welfare over the status quo.

\section{References}

Acemoglu D, Linn J. Market Size in Innovation: Theory and Evidence from the Pharmaceutical Industry. Quarterly Journal of Economics. 2004; 119(3):1049-90.

Banks, J.; Kapteyn, A.; Smith, JP.; van Soest, A. National Bureau of Economic Research Working Paper 11558. Cambridge, MA: National Bureau of Economic Research; 2005. Work Disability is a Pain in the $* * * * *$, Especially in England, The Netherlands, and the United States.

Banks J, Marmot M, Oldfield Z, Smith JP. Disease and disadvantage in the United States and in England. Jama. 2006; 295(17):2037-45. [PubMed: 16670412]

Danzon PM, Wang YR, Wang L. The Impact of Price Regulation on the Launch Delay of New Drugs--Evidence from Twenty-Five Major Markets in the 1990s. Health Economics. 2005; 14(3): 269-92. [PubMed: 15386651]

Finkelstein A. Static and Dynamic Effects of Health Policy: Evidence from the Vaccine Industry. Quarterly Journal of Economics. 2004; 119(2):527-64.

IMS Health. IMS World Review 2006. 2006

Viscusi WK. The Value of Risks to Life and Health. Journal of Economic Literature. 1993; 31(4): 1912-1946. 


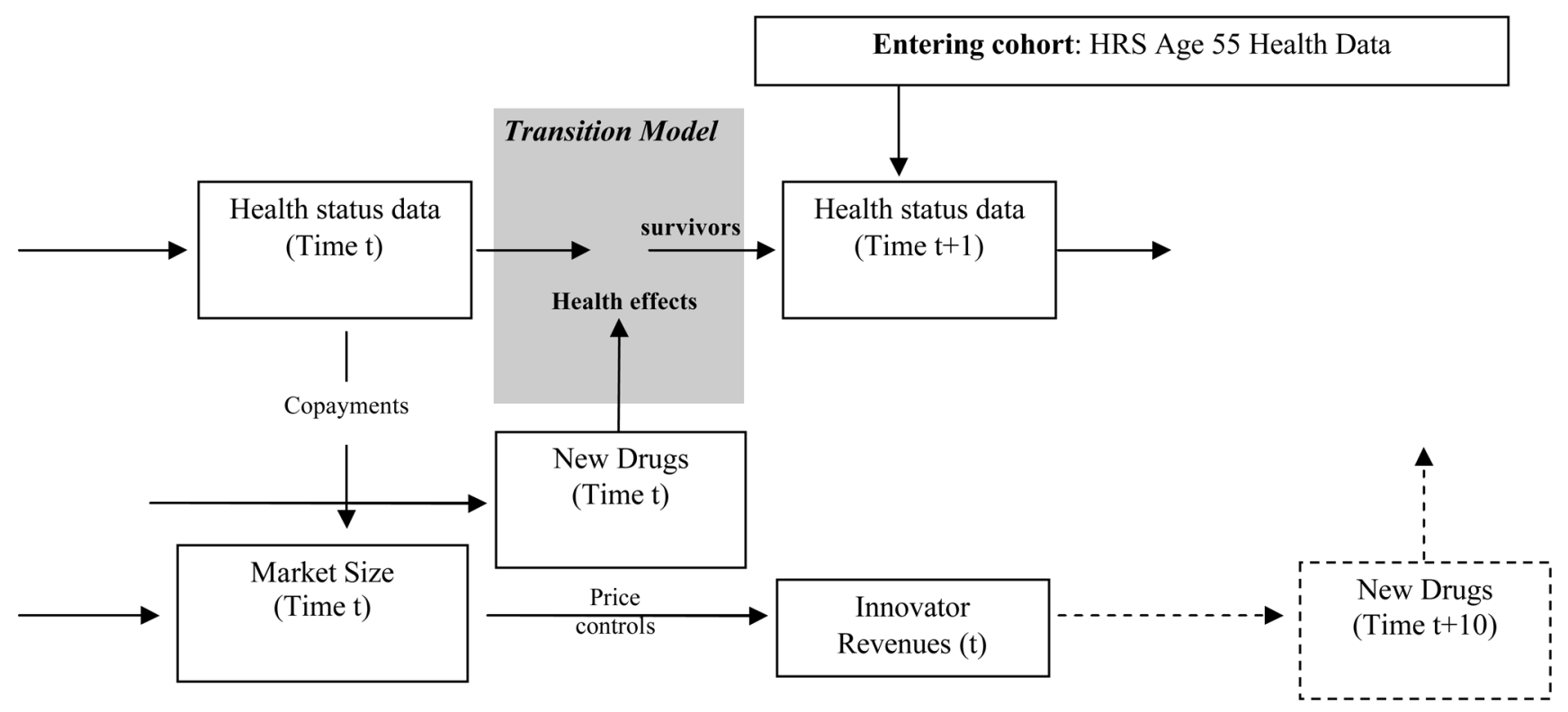

Figure 1.

Structure of GPPM Model. 


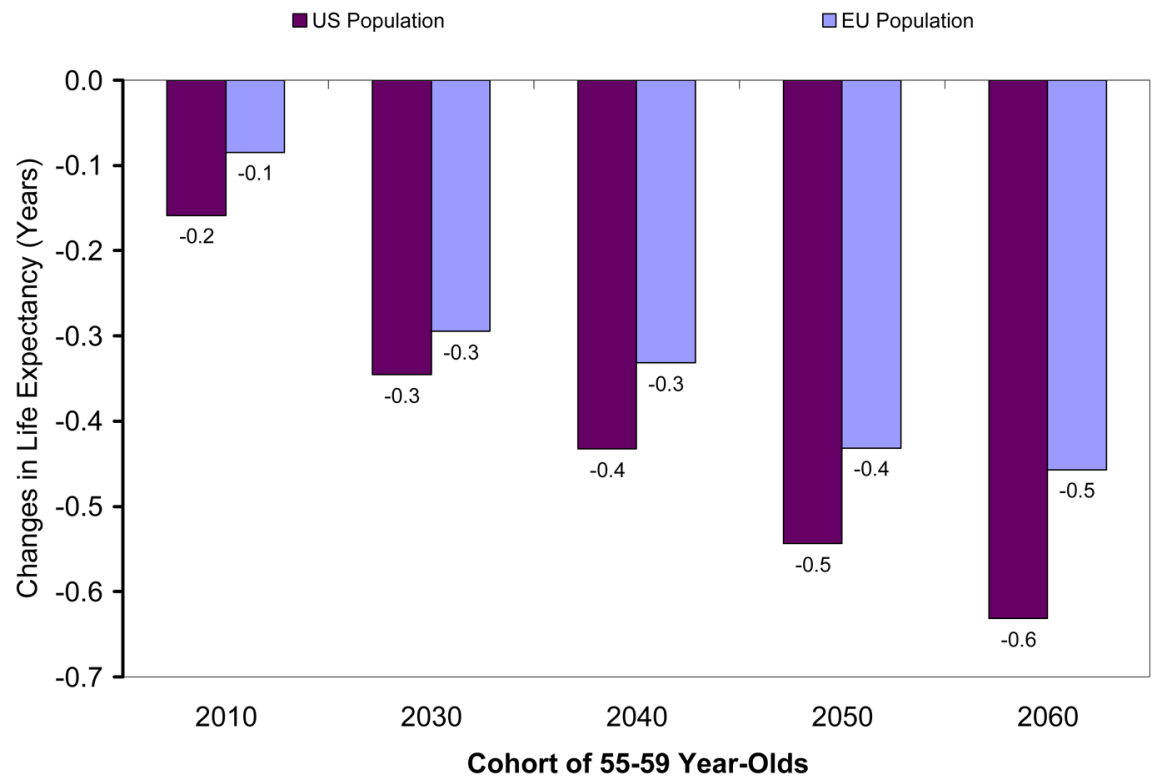

Figure 2.

Effect of US Price Controls on Global Longevity, among 55-59 year-olds in the US and Europe. 


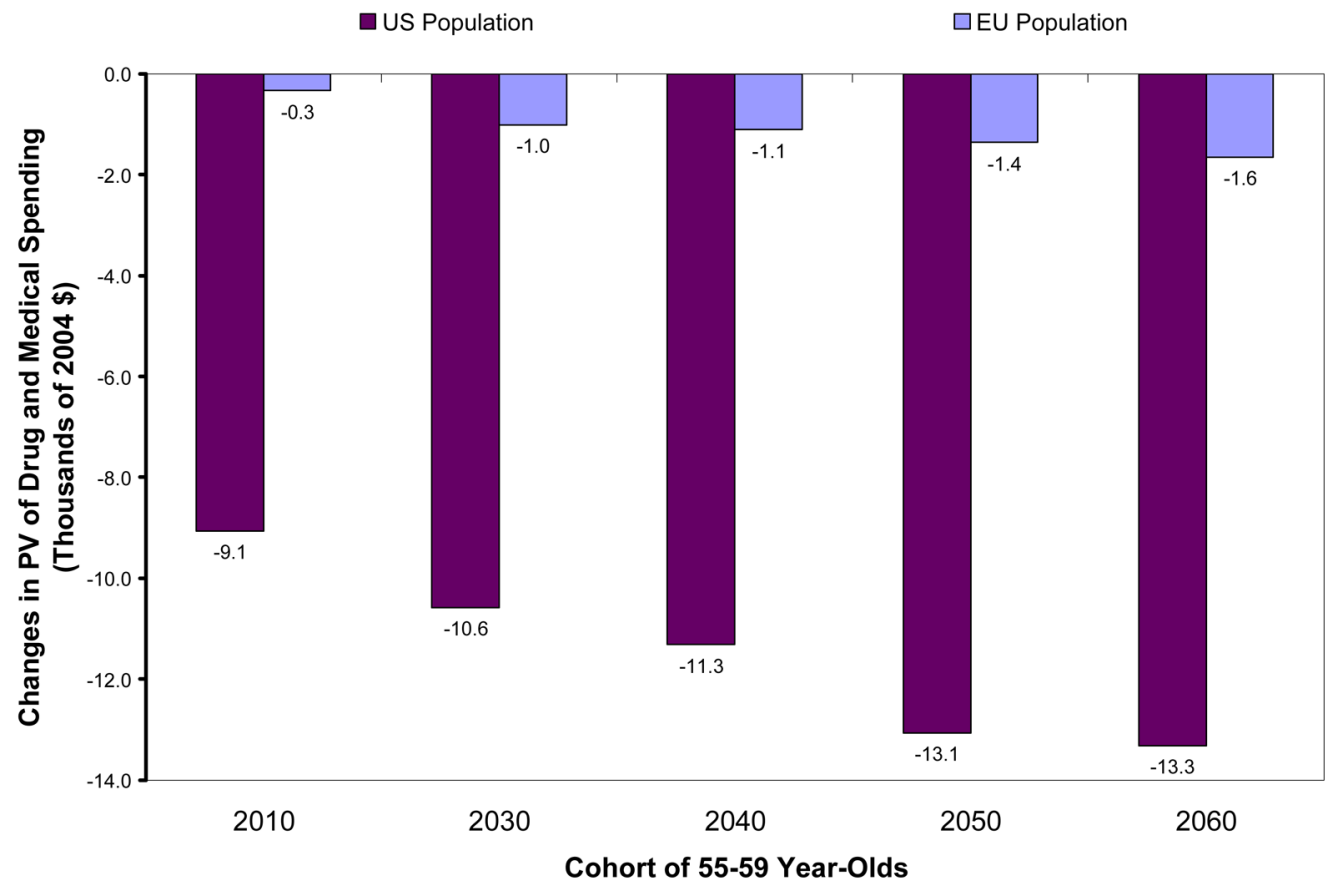

Figure 3.

Effect of US price controls on lifetime drug and health care spending, for cohorts of 55-59 year-olds in the US and Europe. 


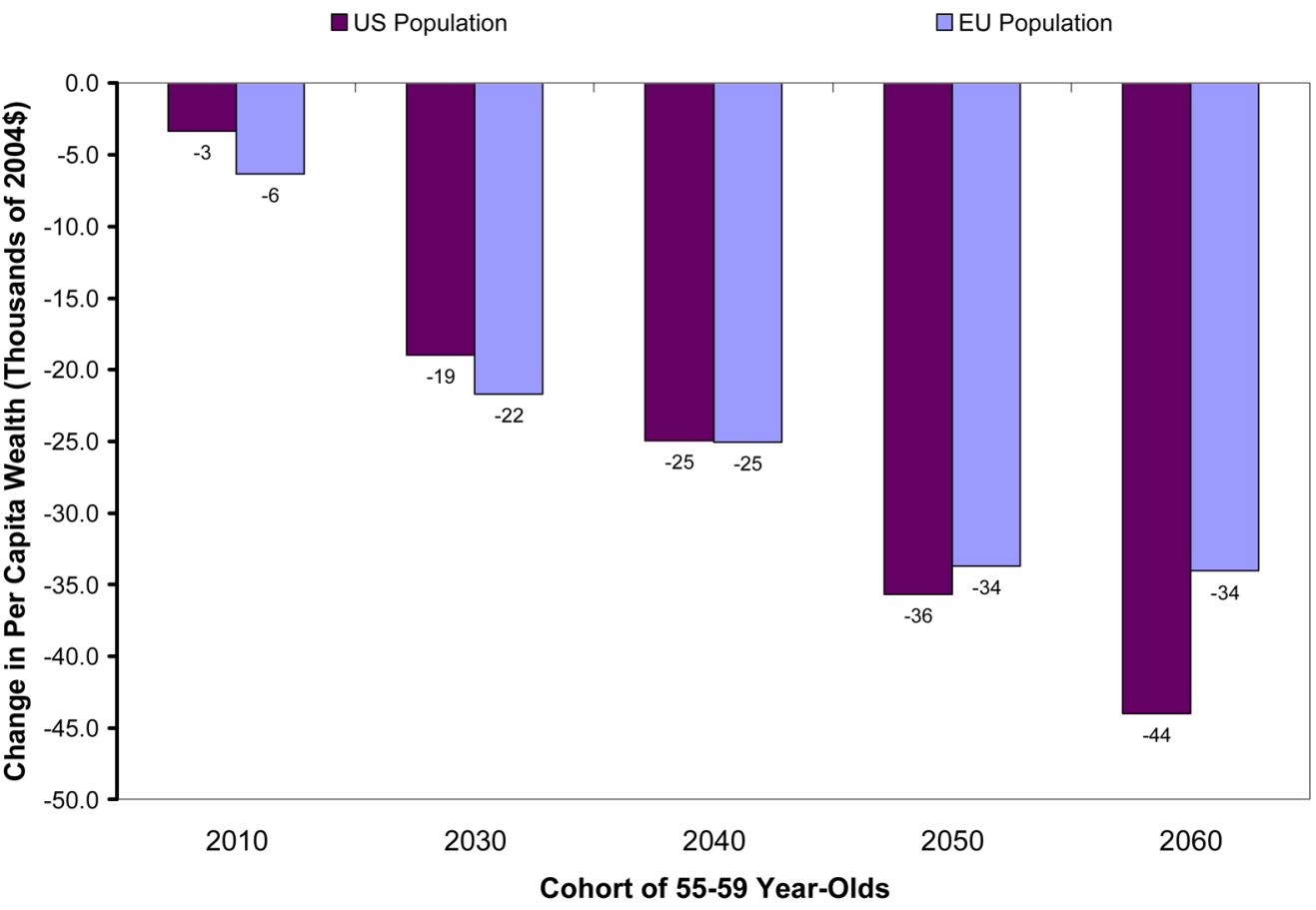

Figure 4.

Net per capita value of US price controls to 55-59 year-olds in the US and Europe. 


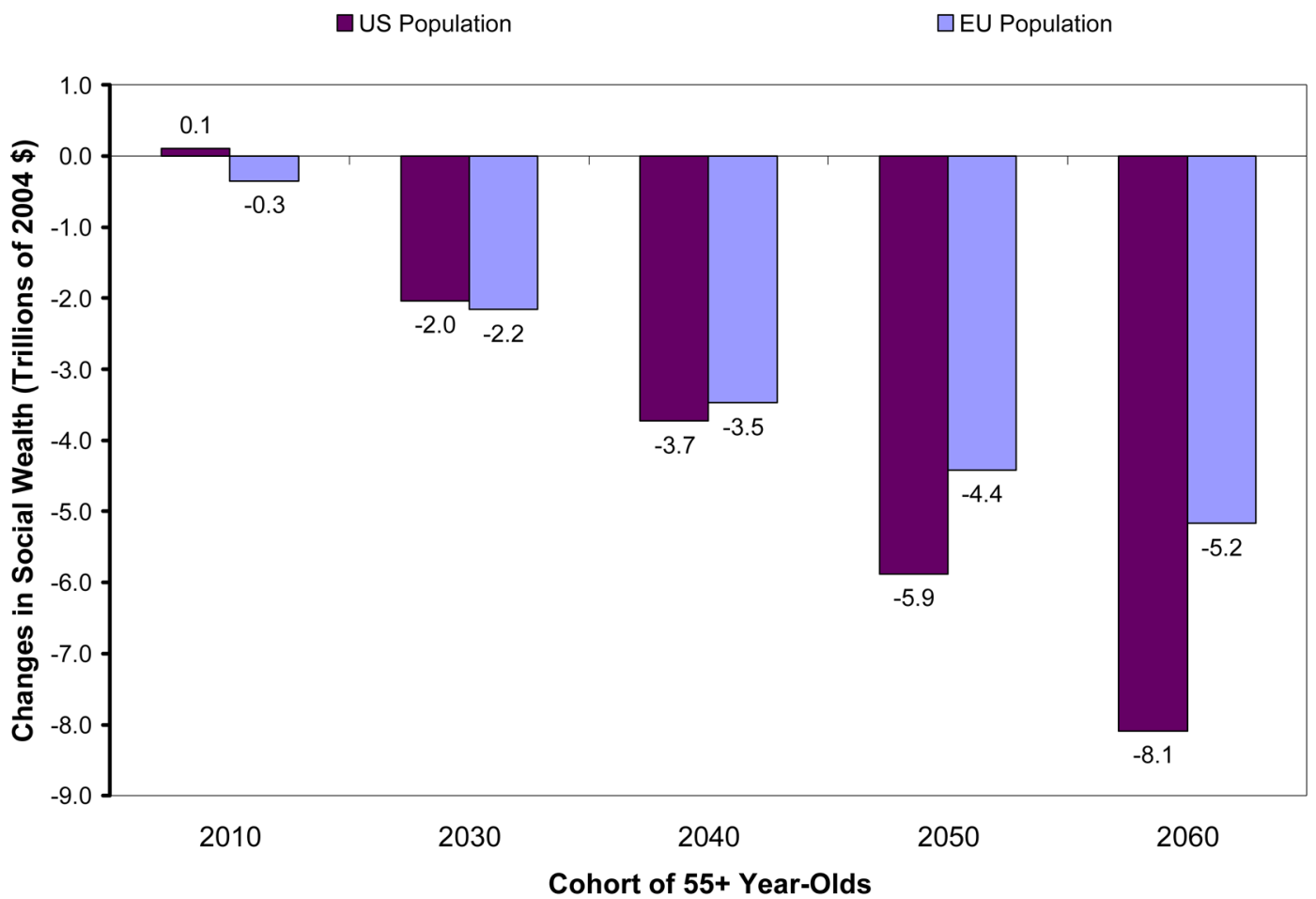

Figure 5.

Net present value of price controls to 55+ population in the US and Europe, by cohort. 


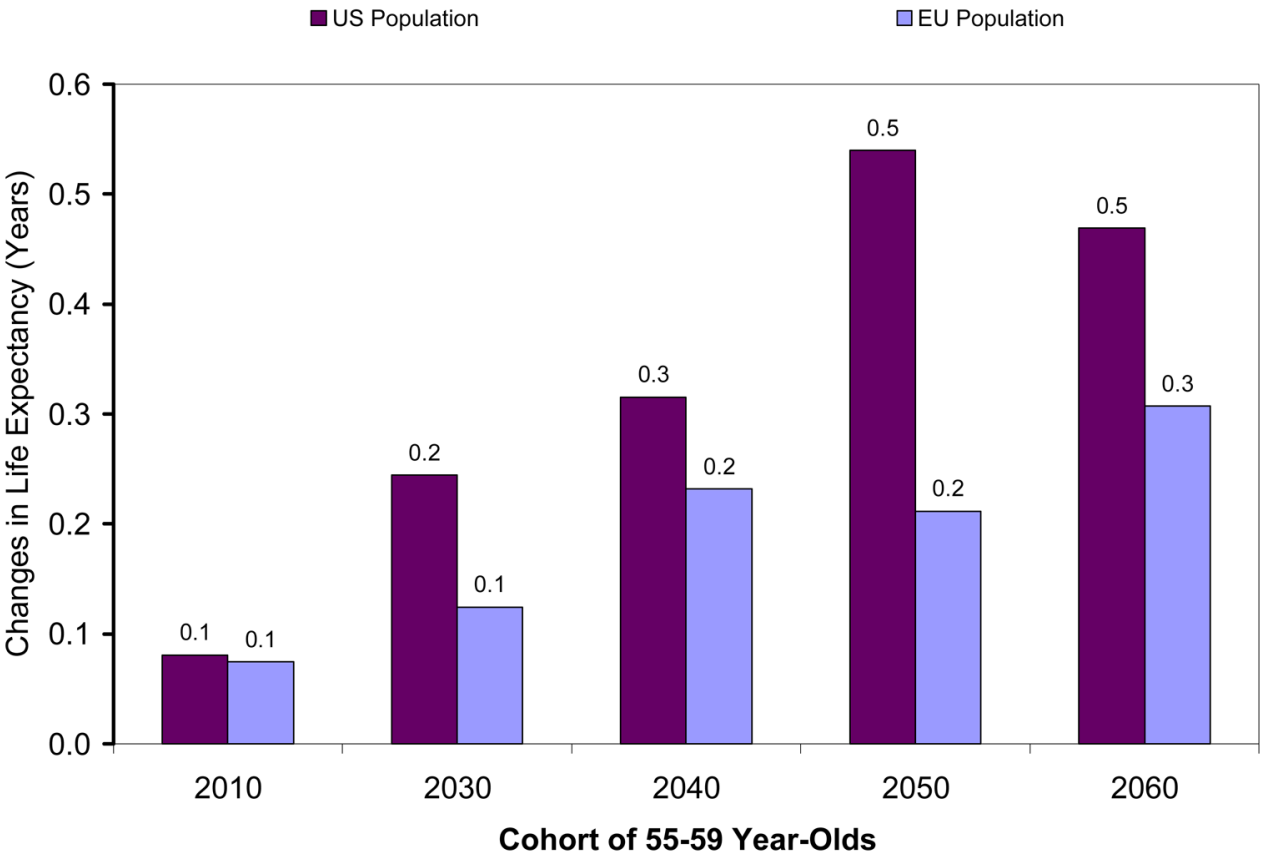

Figure 6.

Effect of US Copay Reductions on Global Longevity, among 55-59 year-olds in the US and Europe. 


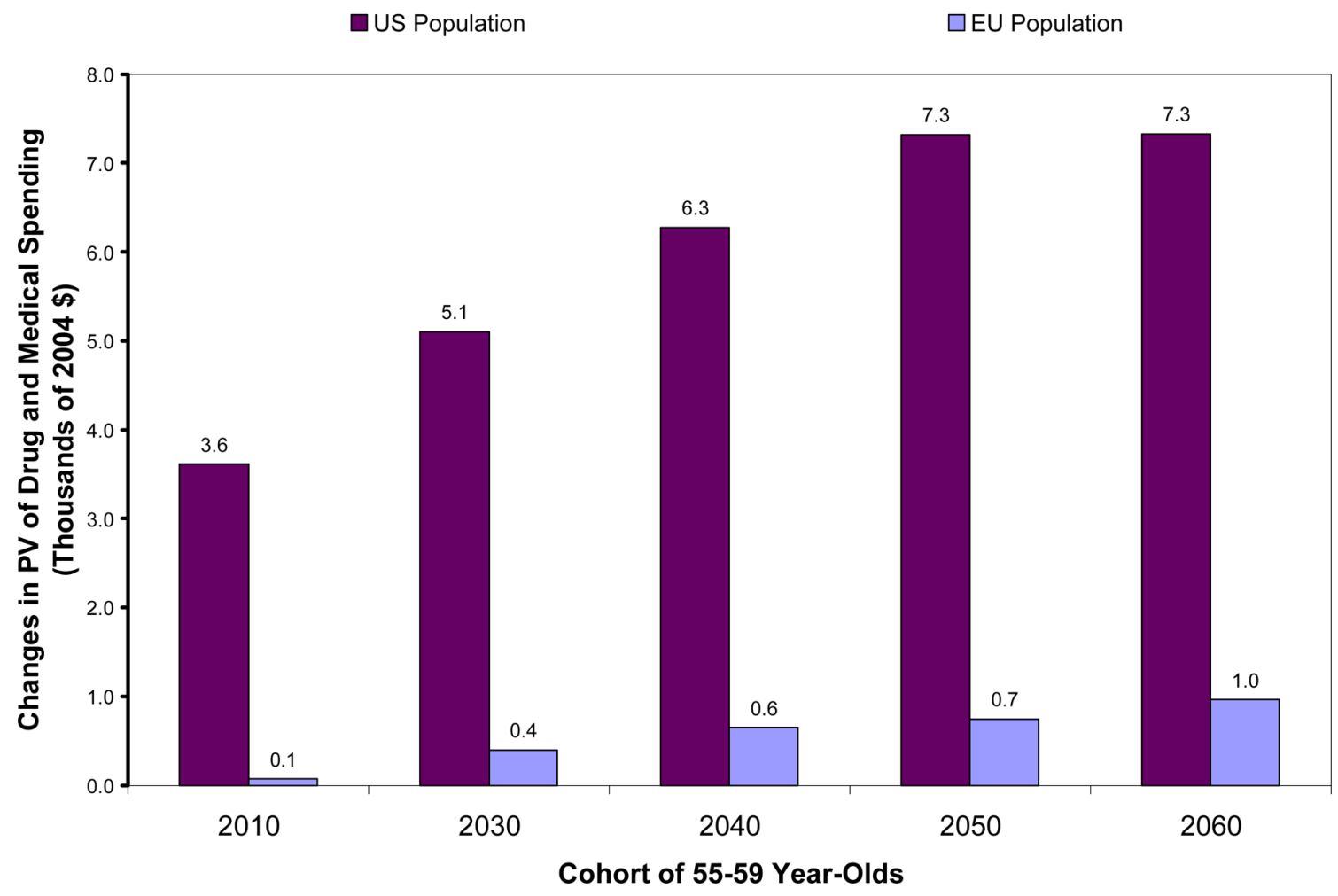

Figure 7.

Effect of US copay reductions on per capita medical spending for 55-59 year-old cohorts in the US and Europe. 
口US Population

$\square E U$ Population

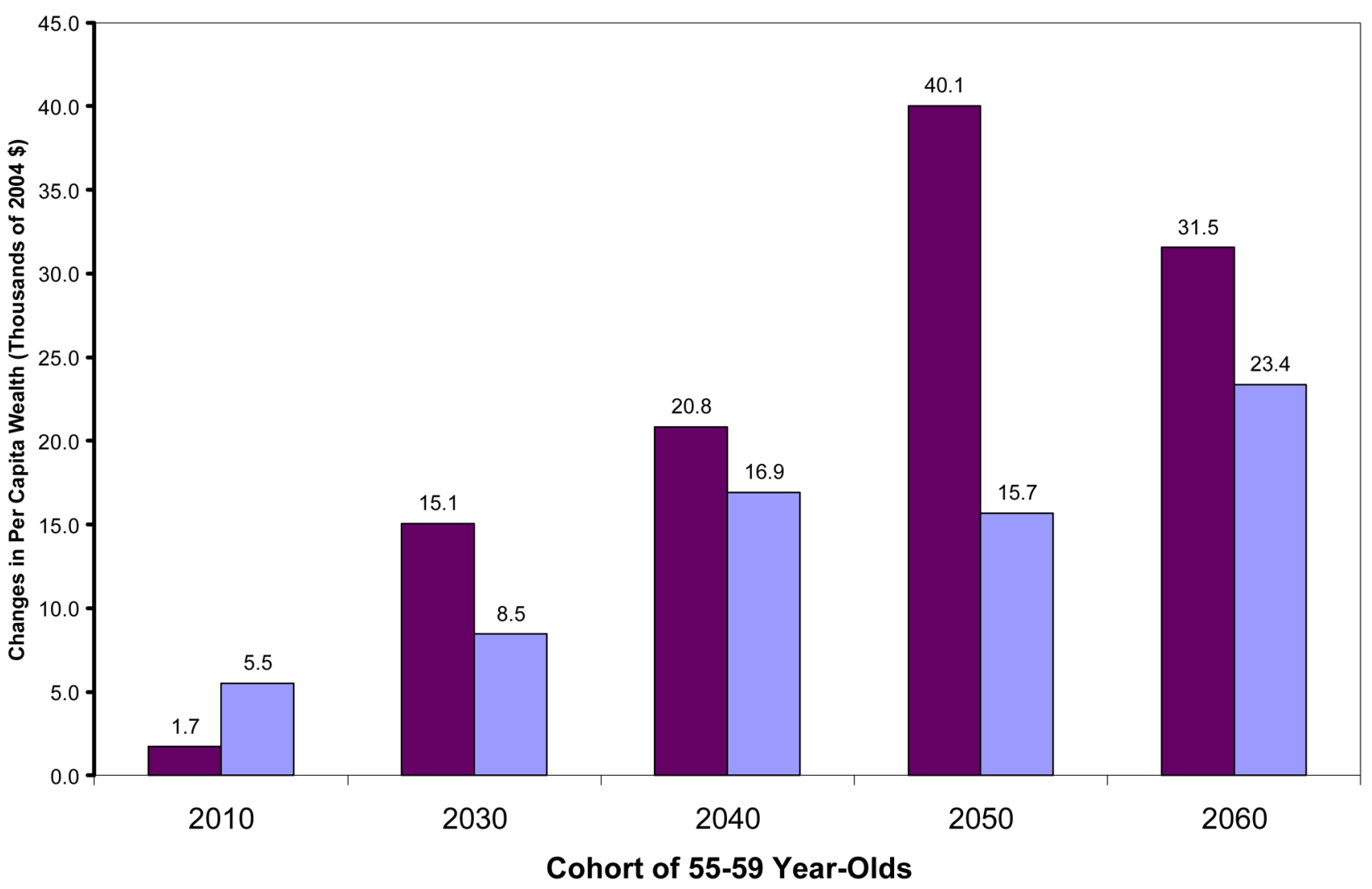

Figure 8.

Net per capita value of US copay reduction to 55-59 year-olds in the US and Europe. 


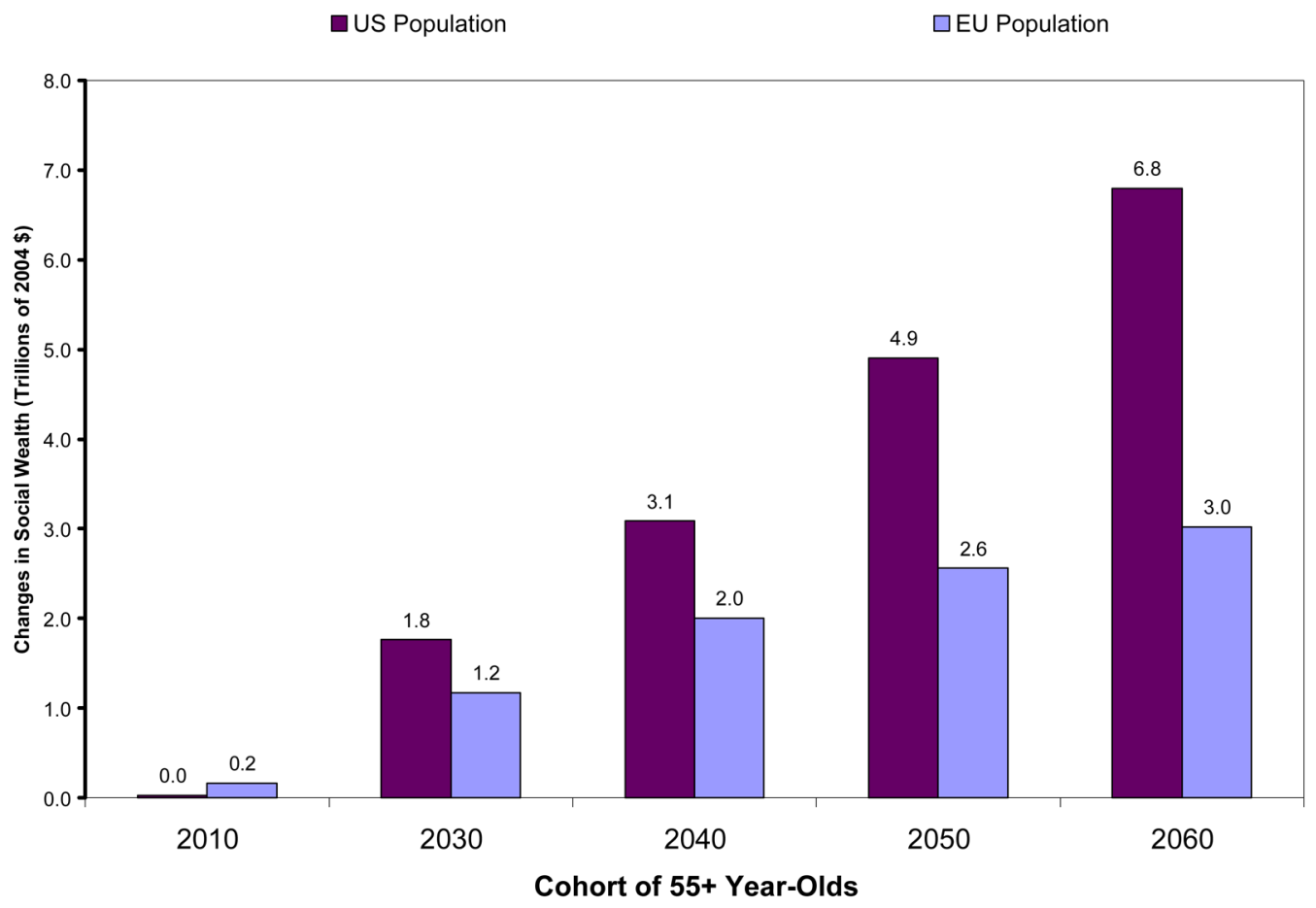

Figure 9.

Net present value of US copay reductions to 55+ population in the US and Europe, by cohort. 


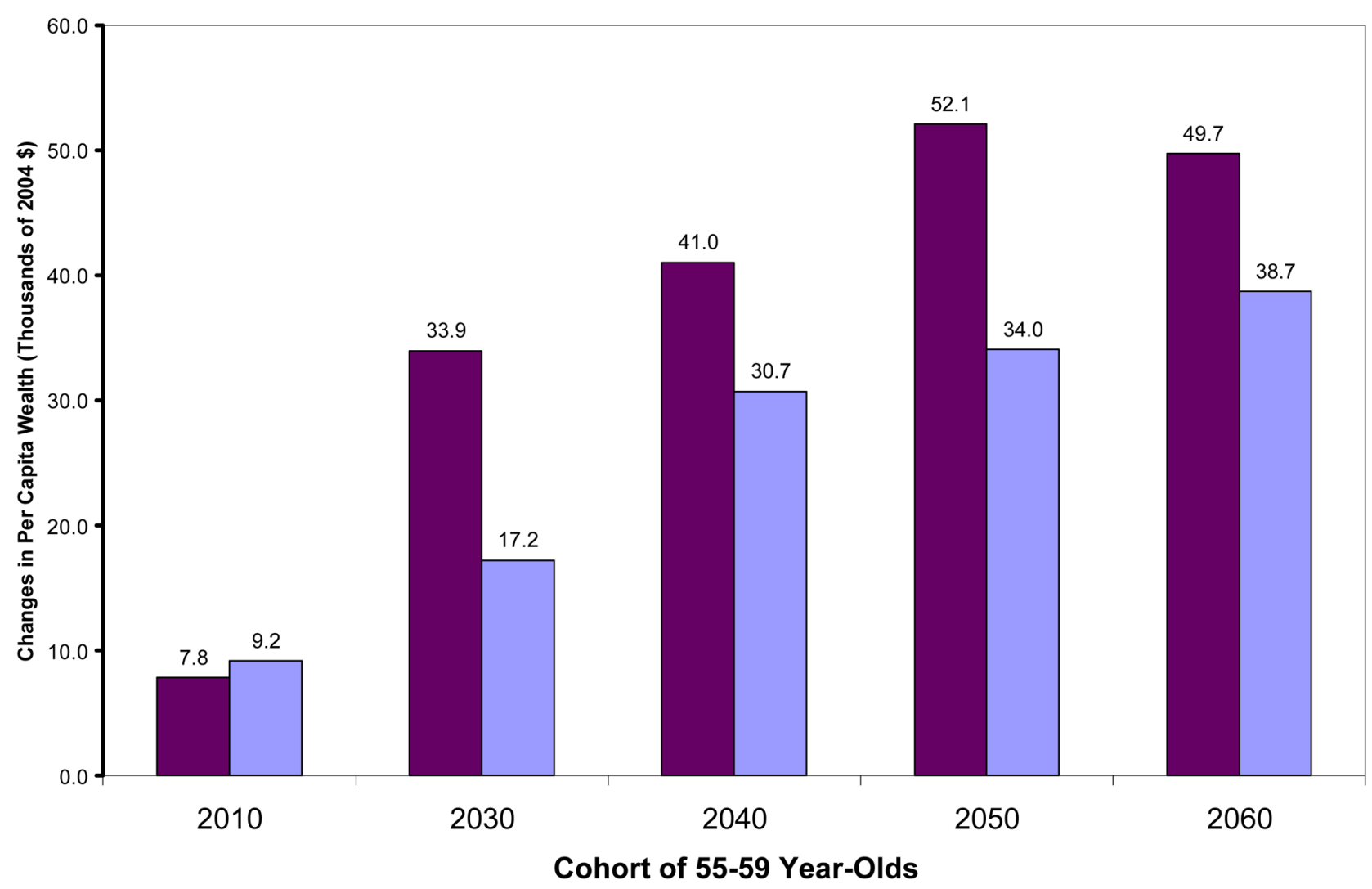

Figure 10.

Net per capita value of repealing EU price controls to 55-59 year-olds in the US and Europe. 


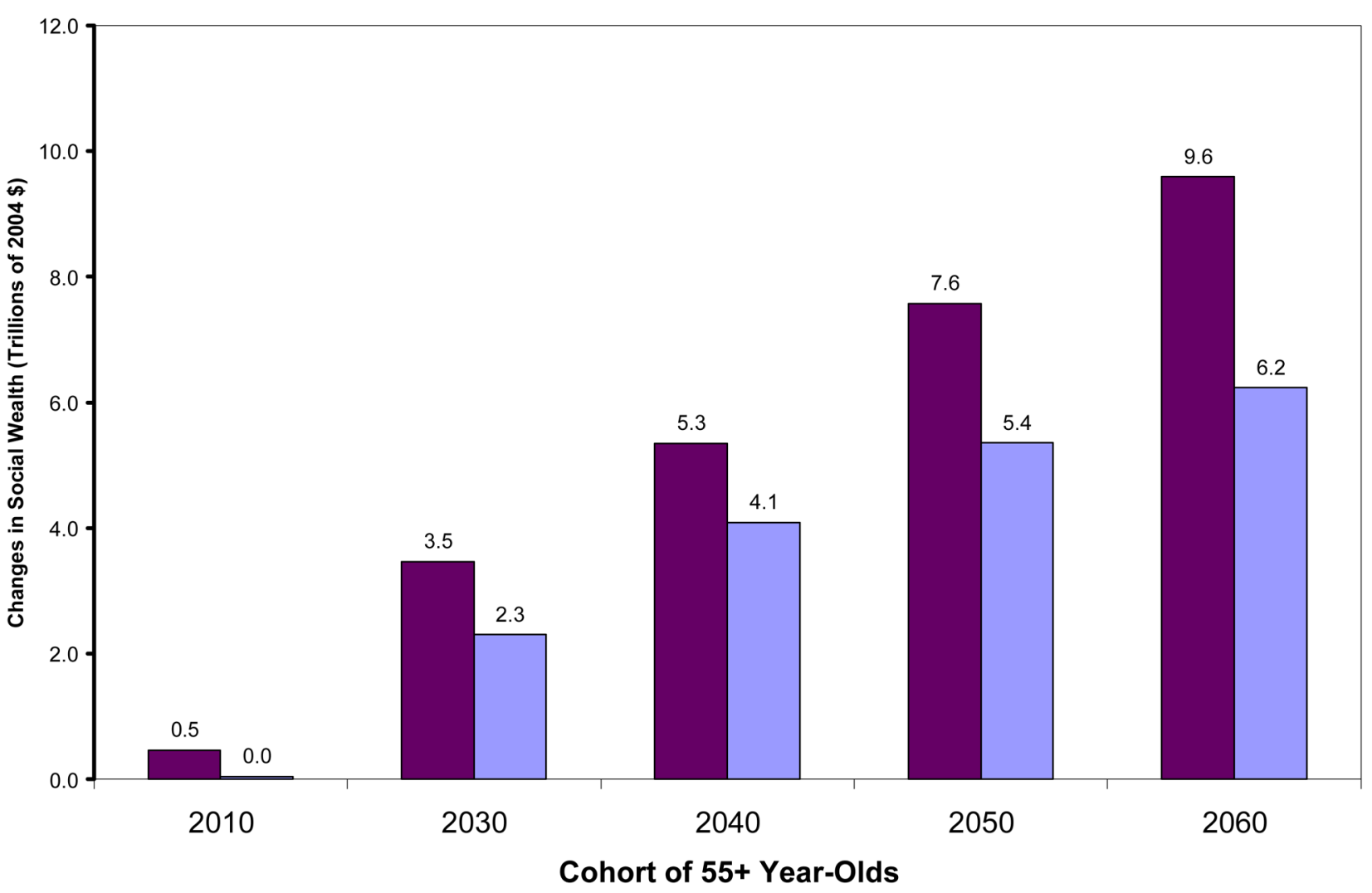

Figure 11.

Net present value of repealing EU price controls to 55+ population in the US and Europe, by cohort. 
口US Population $\square E U$ Population

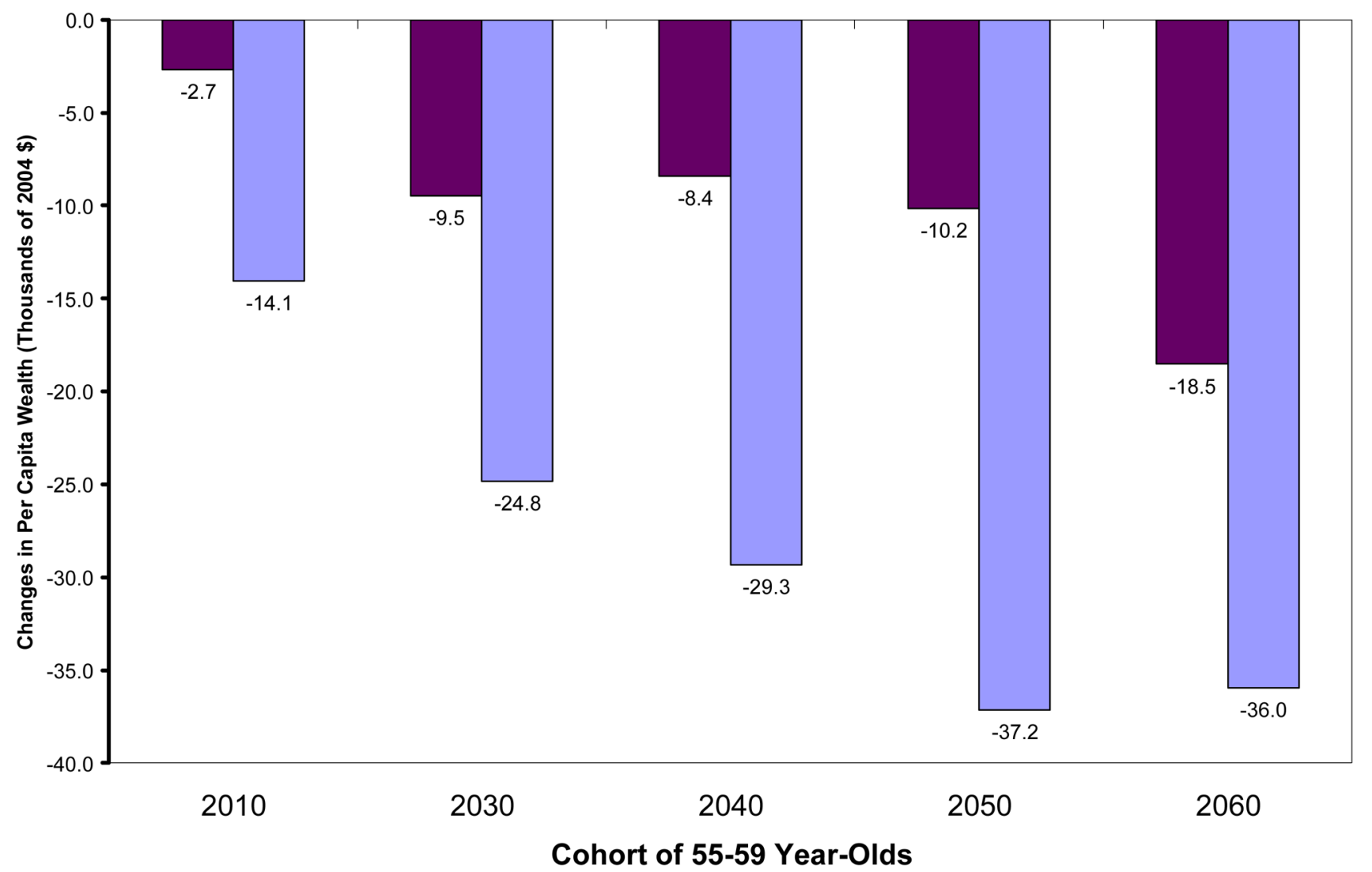

Figure 12.

Net per capita value of increasing EU copays to 55-59 year-olds in the US and Europe. 
口US Population

$\square$ EU Population

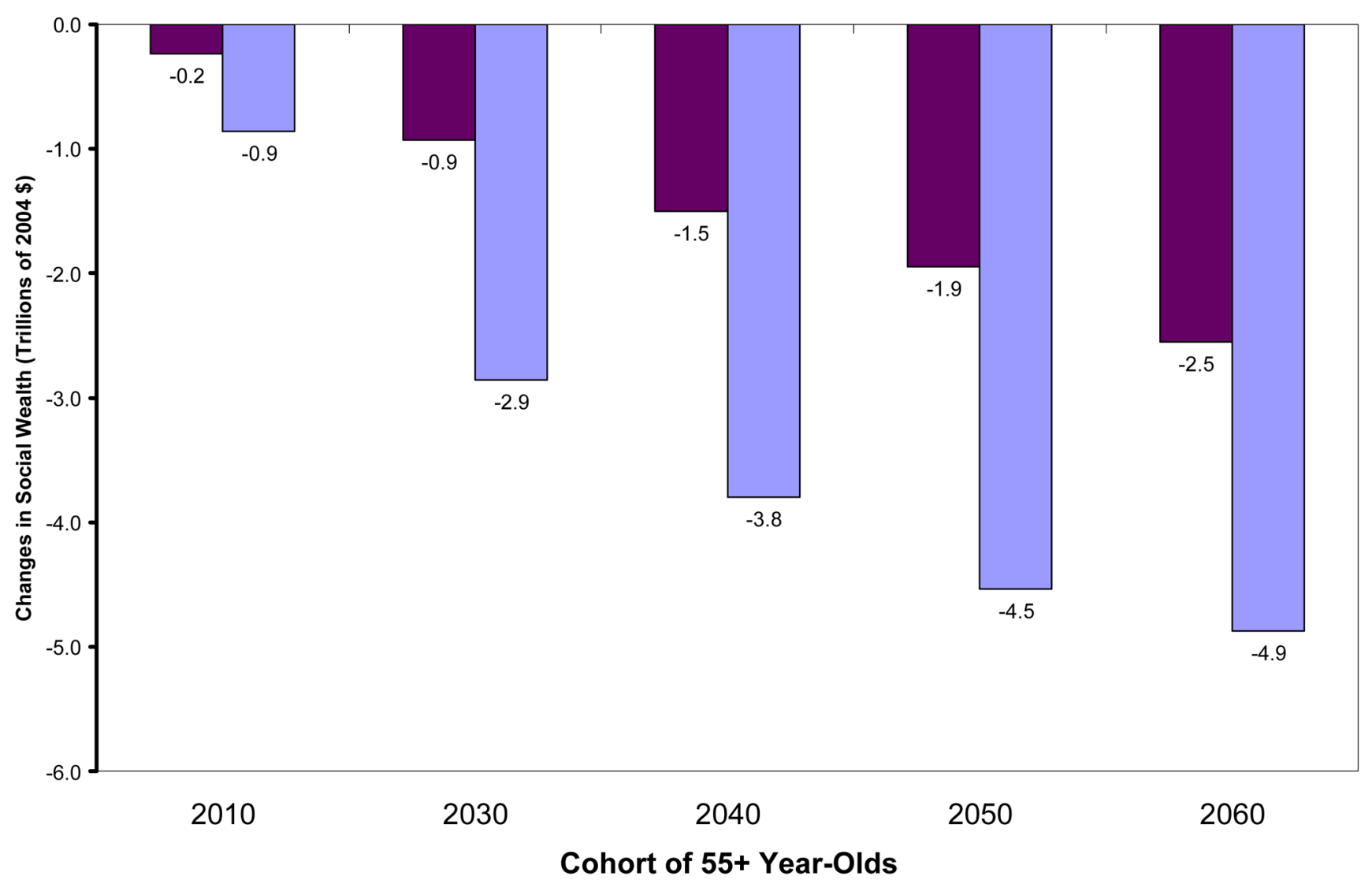

Figure 13.

Net present value of increasing EU consumer copayments to 55+ population in the US and Europe, by cohort. 


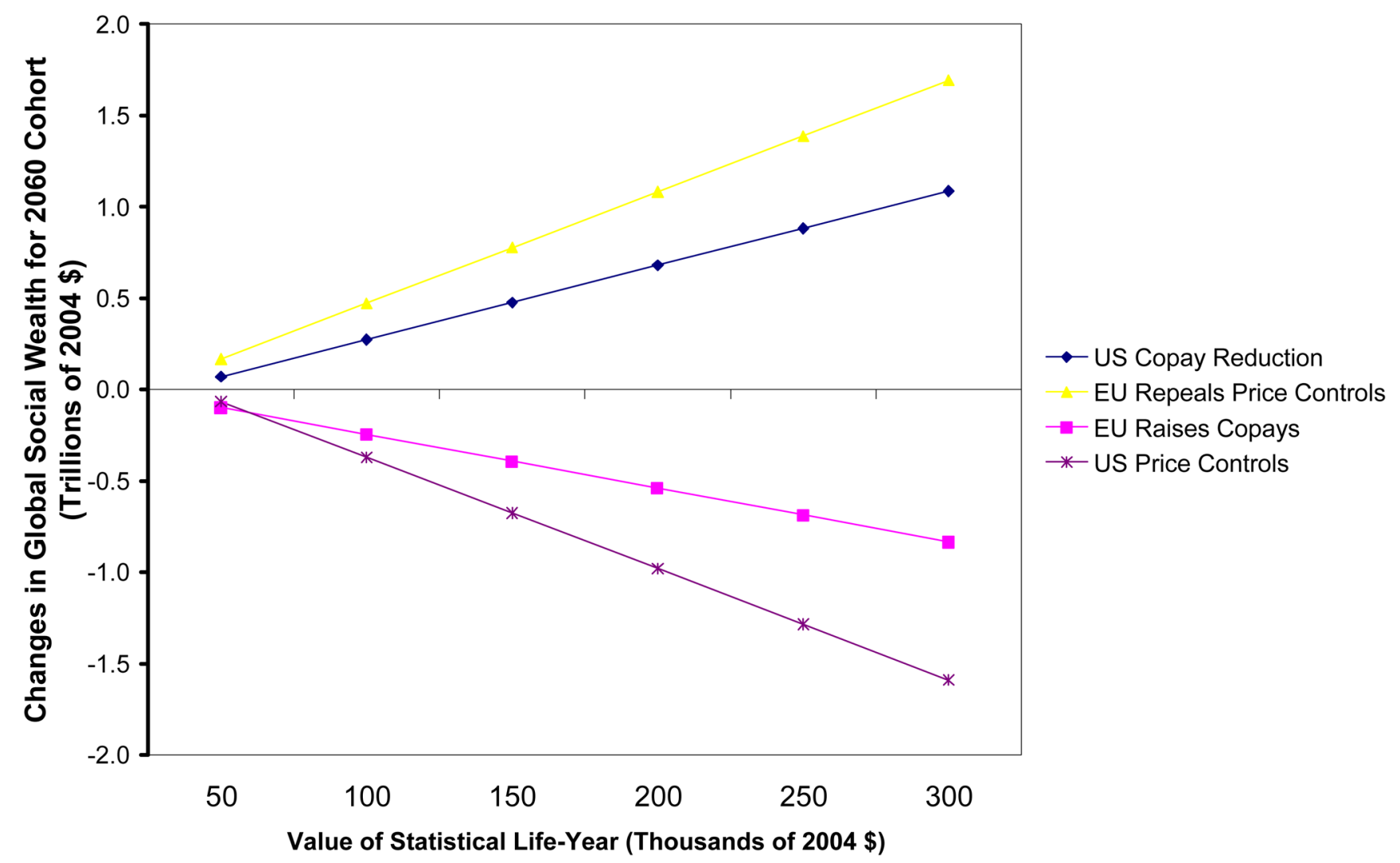

Figure 14.

The Value of a Statistical Life-Year and Model Implications. 


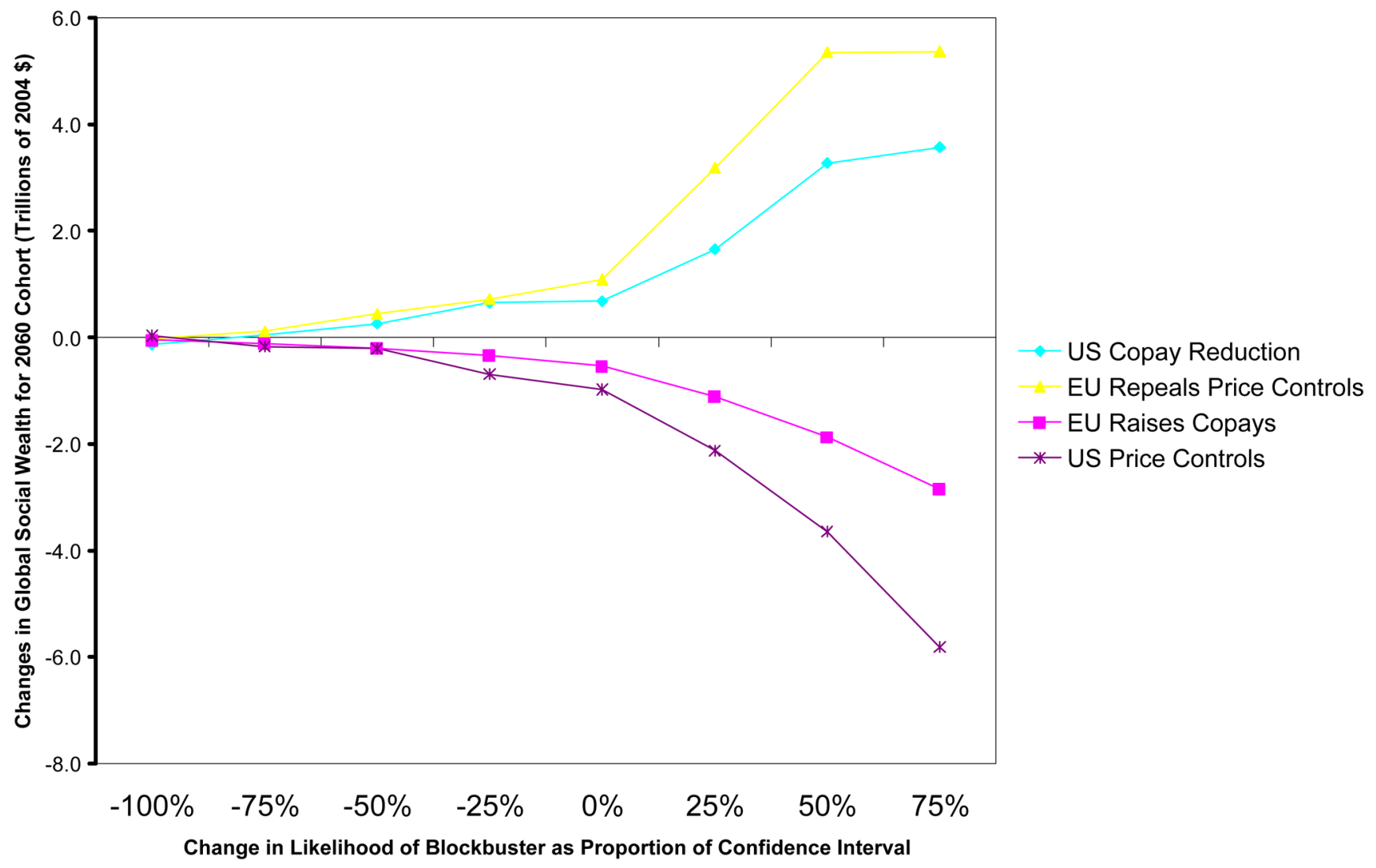

Figure 15.

Likelihood of blockbuster and model implications. 


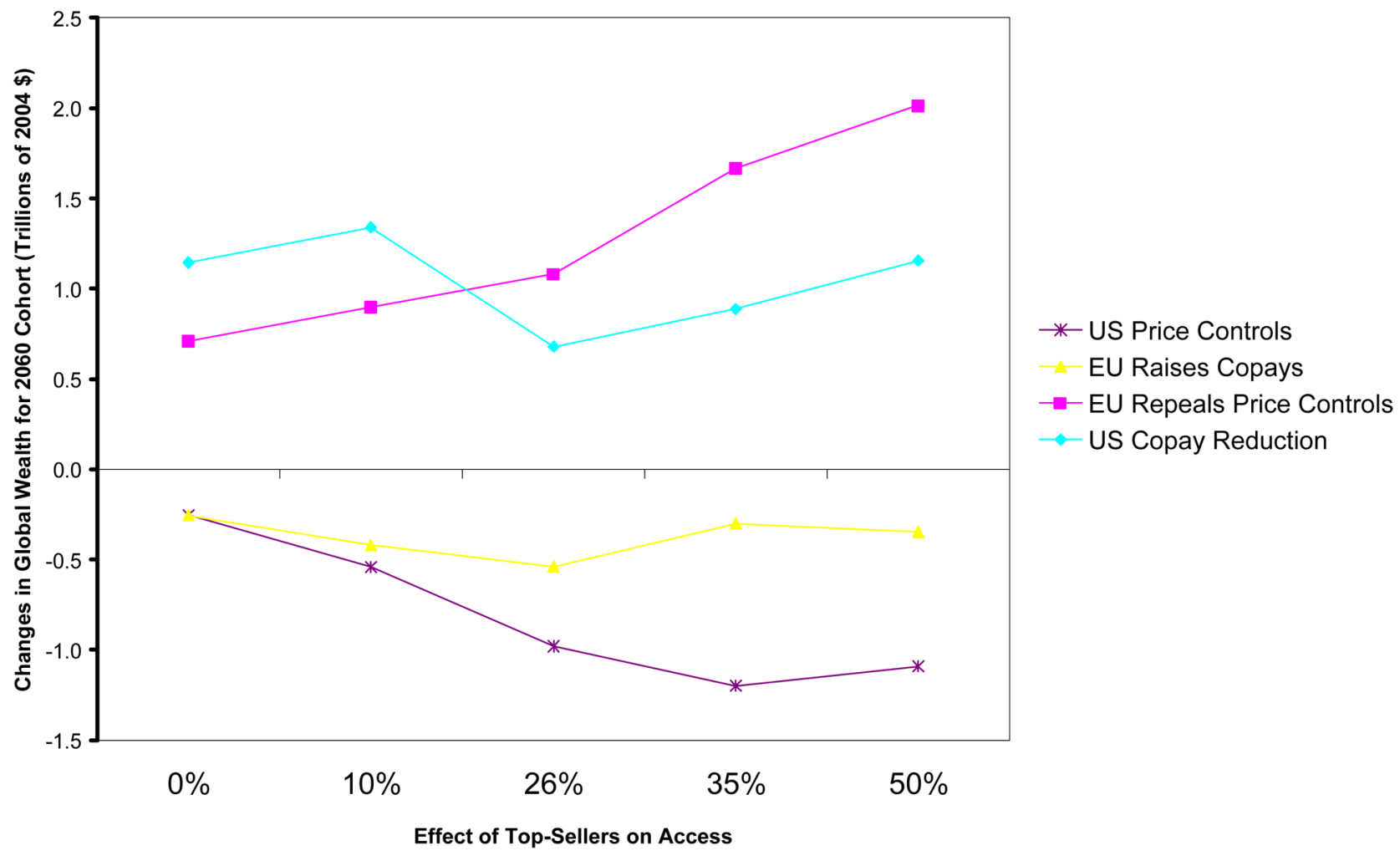

Figure 16.

Access effect and model implications. 


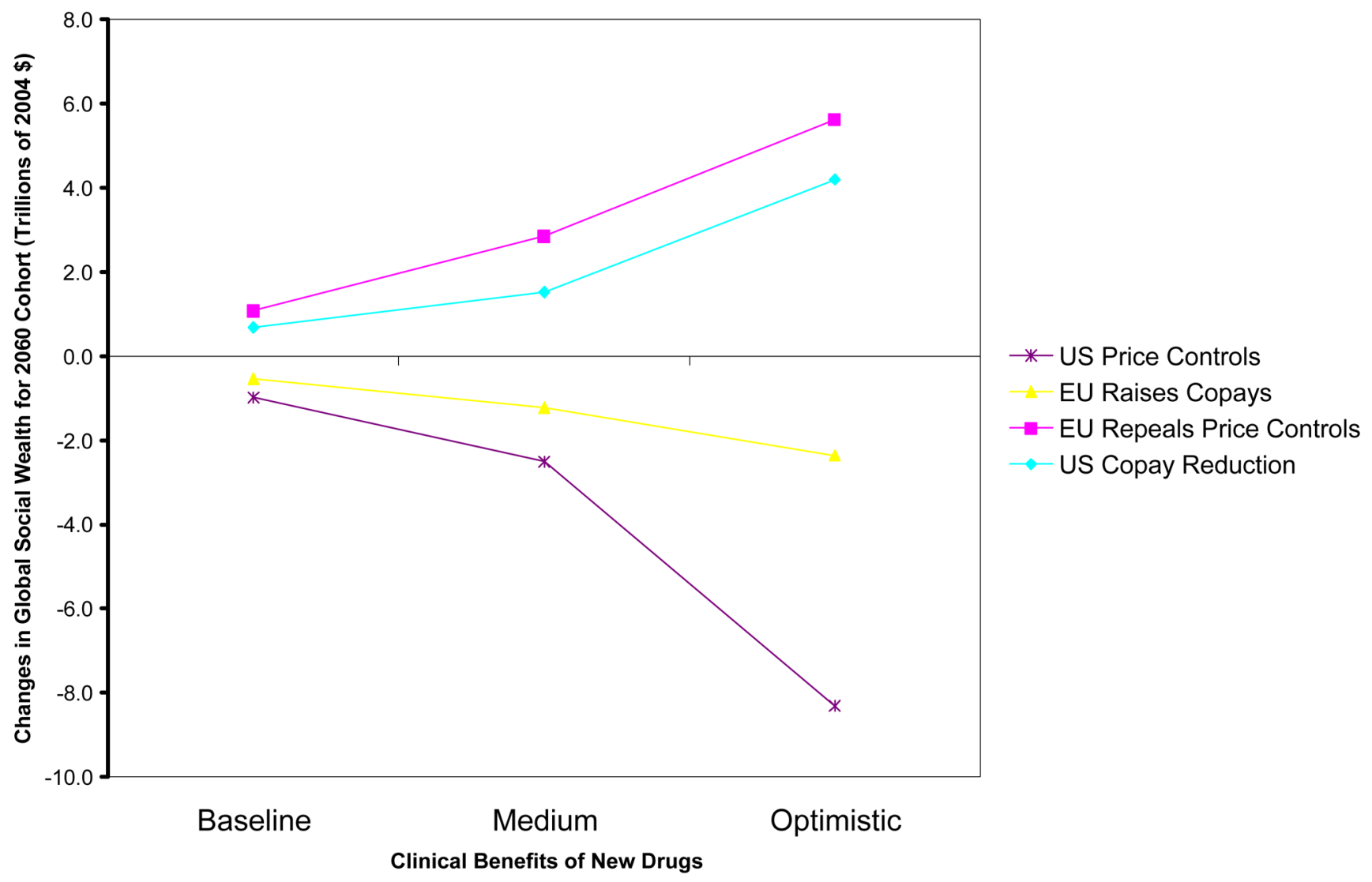

Figure 17.

Clinical effects and model implications. 


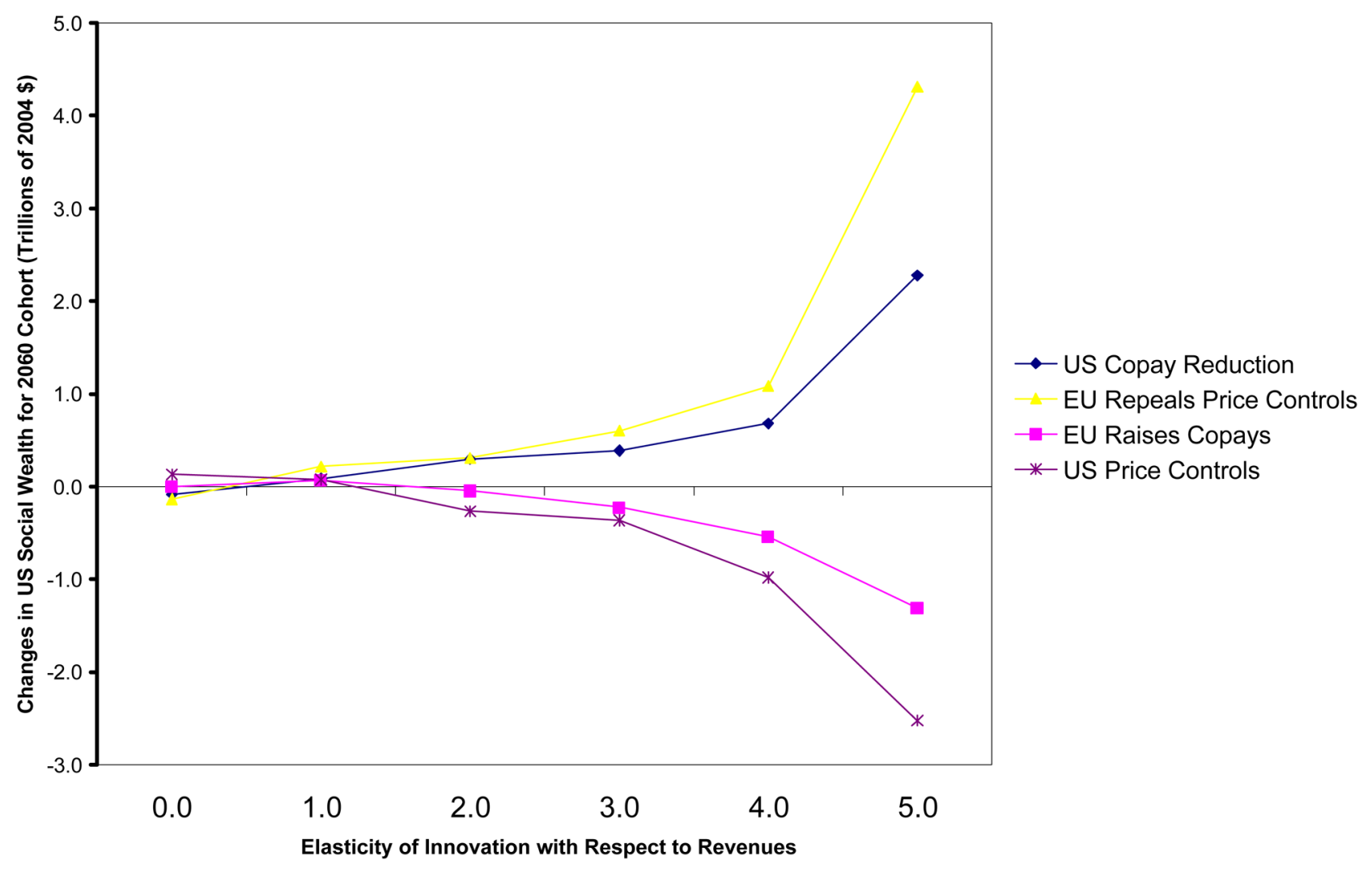

Figure 18.

Innovation-responsiveness and model implications. 


\section{Table 1}

Baseline characteristics of HRS and SHARE samples.

\begin{tabular}{lrr}
\hline Baseline Characteristics & HRS & SHARE \\
\hline age in years & 67.6 & 68.5 \\
less than high school & 0.361 & 0.481 \\
some college education & 0.435 & 0.145 \\
black & 0.089 & 0.000 \\
hispanic & 0.061 & 0.000 \\
male & 0.452 & 0.443 \\
ever smoked & 0.586 & 0.417 \\
obese(BMI>30) & 0.274 & 0.190 \\
heart disease & 0.253 & 0.136 \\
high blood pressure & 0.546 & 0.373 \\
stroke & 0.080 & 0.040 \\
lung disease & 0.102 & 0.063 \\
diabetes & 0.176 & 0.127 \\
cancer & 0.141 & 0.060 \\
mental problem & 0.165 & 0.146 \\
disability(ADL>0) & 0.150 & 0.125 \\
sample size & 16303 & 13515 \\
\hline & & \\
\hline
\end{tabular}


